\title{
Olhando para a Dança do Ventre como uma Possibilidade Feminista: Olhar, gênero e espaço público em Istambul
}

\author{
Işı Eğrikavuk ${ }^{1}$ \\ Berlin University of Arts/UdK - Berlim, Alemanha \\ E-mail: isilegri@gmail.com \\ Tradução de Márcia Donadel \\ E-mail: mdonadel@gmail.com \\ Revisão Técnica de Andréa Moraes \\ E-mail: deadasofi@gmail.com
}

Resumo

Esse artigo discute a forma ancestral de dança do ventre como um exemplo para falar mais a fundo sobre os espaços públicos de Istambul, onde o corpo feminino está constantemente sob vigilância do olhar masculino. Em milhares de anos, a forma ancestral da dança do ventre foi se transformando de um ritual feminino coletivo para uma forma de entretenimento que atende ao olhar masculino. Esse artigo investiga possibilidades de redefinir a dança do ventre como uma contra estratégia feminista para reviver sua essência. Estruturado através da Teoria do Grupo Silenciado (Muted GroupTheory), esse artigo também exemplifica várias obras de arte e estratégias produzidas por mulheres artistas e analisa-os à luz dessa teoria. Além disso, busca refletir a dança do ventre a partir de uma identidade feminista e questiona se essas estratégias artísticas podem ser caminhos para redefinir a dança do ventre como uma prática feminista.
This paper discusses the ancient form of belly dance as an example to speak more in depth about the public spaces of Istanbul, where the female body is constantly under surveillance by the male gaze. Over thousands of years, the ancient dance form of belly dance has been transformed from a collective women's ritual to a form of entertainment that serves the male gaze. This paper looks for the possibilities tore-define belly dance as a feminist counter strategy to revive its essence. Framed by the Muted Group Theory, this paper also exemplifies various artworks and strategies produced by female artists and analyze them in the light of this theory. It also searches for redefining the belly dance as part of a feminist identity and asks whether these artistic strategies could be pathways in re-defining belly dance as a feminist practice. 


\section{Introdução}

Em muitos lugares do mundo, é uma batalha para as mulheres movimentarem-se em espaços públicos sem estarem sujeitas ao olhar de assédio masculino². No entanto, em uma cidade em que igualdade de gênero não é algo adquirido e em que os espaços públicos tendem a ser dominados principalmente por homens, o problema torna-se muito urgente. A ideia desse artigo originou-se da urgência a qual eu e a maioria das mulheres na Turquia enfrentamos todos os dias, e de pensar em maneiras para subverter essa situação.

Meu objetivo nesse artigo é estabelecer a dinâmica de poder criada por hierarquias de gênero em espaços públicos e propor que as mulheres foram silenciadas nesses espaços devido ao olhar de assédio dos homens. Como alternativa, procuro também possibilidades de desafiar essas relações de gênero por meio de uma abordagem teórica e artística que envolve corpo e dança para, finalmente, questionar a formação de um novo método de comunicação que desafie as normas existentes. Como artista e mulher, estou sempre buscando maneiras de subverter os códigos de gênero na cidade em que moro. Eu sei que a tentativa é também coletiva, portanto, em todo o artigo, eu cito como as mulheres artistas desenvolveram suas próprias estratégias para desafiar a hegemonia dominante.

1 Işıl Eğrikavuk estudou literatura ocidental na Boğaziçi University (Istanbul), então estudou no Schoolof The ArtInstitute em Chicago (SAIC) com uma bolsa de estudos da Koç Foundation, no seu Mestrado em Performance Art. Ela lecionou arte e comunicação na Istanbul Bilgi University, no período entre 2009-2017. Desde 2017, ela mora em Berlin e leciona na Universität der Künste (UdK), no Media and Communication Department. Ela completa seu PhD em 2021. Éco-vencedora do primeiro prêmio de arte contemporânea da Turquia, o Full ArtPrize, em 2012. Ela também ficou em primeiro lugar no financiamento SPOT ProductionFund para artistas. Ela participou de numerosas exposições internacionais, residências e seu trabalho tem sido publicado em periódicos acadêmicos locais e internacionais. E-mail: isilegri@gmail.com. ORCID ID: 0000-0003-4390-9540.

2 Tradução de man gaze,um olhar invasor. Não se trata somente de um olhar, no sentido de ver, observar, mas de um olhar de assédio. N.T.
Por meio desse artigo, observo também possibilidades de redefinir a forma de dança do ventre ancestral ${ }^{3}$ como prática feminista e buscar respostas para superar a visão normativa de que essa dança é uma forma de entretenimento que serve ao olhar masculino. A dança poderia, de fato, ser redefinida como prática feminista? Poderia ser propriedade de mulheres que se descrevem como feministas? Eu também tento responder a essas questões à luz do trabalho de artistas feministas contemporâneas que abriram o caminho para outras mulheres ao longo da história.

\section{Teoria do Grupo Silenciado}

A Teoria do Grupo Silenciado é uma teoria originada das pesquisas de dois antropólogos culturais, Edward e Shirley Ardener, no final dos anos de 1960. Mostra como a linguagem pode ser usada como uma ferramenta para um grupo de pessoas na sociedade, bem como enfoca a forma pela qual as mulheres foram silenciadas ao longo da história pelo gênero dominante, os homens. Os Ardeners relatam que o problema de silenciamento existe para muitos grupos culturais que estão em relacionamentos assimétricos. Seus interesses e considerações não são apenas sobre diferenças de gênero, mas também uma série de outras diferenças marginalizadoras. Ainda, apesar do fato de que a Teoria do Grupo Silenciado pode ser usada para falar sobre qualquer grupo minoritário que tenha sido emudecido ao longo da história, Shirley Ardener concentra-se especialmente no problema de domínio sobre as mulheres. Ardener questiona se "todos na sociedade têm participado igualmente na geração de ideias e discurso" (ARDENER, 2005, p. 51) e como isso se reflete na linguagem, especialmente na linguagem utilizada para descrever as representações, comportamentos, códigos e normas em relação às mulheres.

Ardener pesquisa como as mulheres são mencionadas mesmo em estudos acadêmicos e

3 Ancestral, como tradução para o vocábulo ancient, devido à ligação da dança com rituais de fertilidade oferecidos à deusa Ísis e à deusa Ichtar na Mesopotâmia e no antigo Egito, citados em Buonaventura (1998, ver Referências). N.T. 
nas formas comuns de comunicação. Ela exemplifica como as mulheres são descritas como "esposas", colocadas entre parênteses nas pesquisas, ou apresentadas como iguais a "cavalos e bedida"4 nos estudos acadêmicos ou nos principais meios de comunicação. Ela cita outra acadêmica, Kirsten Hastrup, e conclui que "enquanto o homem é generalizado, as mulheres são especificadas" (ARDENER, 2005, p. 52). Ardener também fala sobre como as mulheres ao longo da história foram silenciadas em diferentes segmentos da vida social:

Hoje, eu apenas gostaria de enfatizar que o silenciamento por grupos dominantes através do controle do discurso de dominação é refratado e incorporado em muitos espaços sociais diferentes: em arranjos de assentos, prestígio e poder, religião e, claro, discurso. (ARDENER, 2005, p. 51)

Da mesma forma, Ardener vai mais longe ao perguntar se os grupos da sociedade criaram realidades diferentes ou sistemas de valores que não têm o reconhecimento adequado nas representações dominantes da sociedade. Ela se concentra especialmente em como as mulheres eram sistematicamente excluídas em muitos níveis diferentes. Usando a teoria de Ardener de grupos silenciados como a base do meu argumento, mas transportando-a para geografia e época diferentes, gostaria de problematizar como o espaço público na Turquia tem sido utilizado como um lugar de controle sobre os corpos femininos e, assim, como as mulheres são silenciadas e tornadas invisíveis pelos homens. A fim de comprovar meu ponto de vista e construir meu argumento, vou primeiro citar vários estudiosos e seus estudos no campo das artes visuais. Por fim, vou abrir uma discussão para perguntar se uma abordagem artística poderia tornar-se uma alternativa para desafiar as normas existentes de comunicação e entre gêneros na Turquia de hoje.

$4 \mathrm{~A}$ autora não se refere aqui ao contexto da Turquia, e sim, ao olhar do colonizador (ocidental). Quando as mulheres são comparadas a cavalos, ela se refere à Austrália. Outra referência tem origem no Reino Unido, em uma publicação acadêmica de um autor britânico.
No entanto, estou ciente de que tal contextualização poderia facilmente dar lugar a uma dualidade leste-oeste na discussão de gênero e feminismo. Ao falar sobre as mulheres do terceiro mundo, fazendo referência especificamente à Turquia, abstenho-me de produzir um único tipo de representação de muIheres do terceiro mundo. Assim como ChandraTalpadeMohanty descreve muito bem em seu ensaio Under Western Eyes ${ }^{5}$, eu também prefiro analisar o caso da Turquia de um lugar transnacional. Para dizer isso nas palavras de Mohanty, "gostaria de analisar mais especificamente, portanto, é a produção da 'mulher de Terceiro Mundo' como um sujeito monolítico único em alguns textos feministas (ocidentais) recentes (MOHANTY, 2003, p. 3336).

\section{Espaço público e suas hierarquias}

A definição de espaço público já é uma questão problematizada. Em seu livro A World of Strangers, a socióloga Lyn Lofland pergunta o que significa para milhões de estranhos existirem lado a lado em uma cidade. Segundo Lofland, o comportamento em espaços públicos envolve observar o outro. Lofland argumenta ainda que humanos privatizam o espaço público por meio de "transformações locacionais" (LOFLAND, 1973, p. 118). É através desses territórios manufaturados que os humanos privatizam o espaço público e aprendem a agir, se vestir e se comportar.

No entanto, quais são os limites ao observar os outros? Como tais transformações de localização se aplicam em lugares onde o espaço público é dividido em um contexto de segregação de gênero? Como papéis específicos de gênero moldam o comportamento em espaços públicos? Quais são os papéis esperados de homens e mulheres em espaços públicos? Eles abrem limitações ou oportunidades para cada gênero? Em uma cidade como Istambul, essas questões se tornam vitais.

5 Publicação em português: MOHANTY, ChandraTalpate. Sob olhos ocidentais. Tradução de Ana Bernstein. Copenhague/Rio de Janeiro: Zazie Edições, 2020.

6 Na publicação em português: MOHANTY, 2020, p. 7-8. 
Em seu livro, Behavior in Public Spaces, o sociólogo ErvingGoffman relata que no diagnóstico de transtorno mental, psiquiatras costumam citar aspectos do comportamento do paciente que são "inapropriados para a situação". De acordo com Goffman, a interação entre dois indivíduos ocorre primeiramente através de uma "interação difusa" quando alguém coleta informações sobre outra pessoa olhando para ela (GOFFMAN, 1963, p. 24). Goffman apresenta uma segunda etapa, uma interação focalizada, quando as pessoas se aproximam e cooperam abertamente para manter um único foco de atenção, tipicamente revezando-se na conversa. Sob tal categoria, ele passa a definir uma "desatenção civilizada" quando uma pessoa observa os demais retirando a atenção do falante, de modo a expressar que ele não constitui um alvo de especial curiosidade (GOFFMAN, 1963, p. 84).

Essa desatenção respeitadora parece saudável em uma sociedade, quando se observa o outro por curiosidade. No entanto, há uma linha tênue onde o "civilizado" se torna "grosseiro" e cruza a fronteira da curiosidade, transformando-a em olhar fixo e violação do outro. Acadêmicos, como Carol Gardner levam os pontos de Goffman ainda mais além, a ponto de considerar esse comportamento como assédio. Carol Gardner inverte esta categoria e introduz o termo, "atenção não-civilizada" que envolve formas de assédio e abuso em público (GARDNER, 1995, p. 112).

O que me interessa é essa atenção não-civilizada nos termos de Gardner e como esse ato grosseiro de olhar para o corpo de alguém, geralmente de homem em relação à mulher, torna-se normal no espaço público. Esse ato de olhar fixo é tão comum em Istambul a tal ponto que, enquanto uma mulher anda na rua durante o dia, pode contar numerosos homens olhando para seu corpo ao mesmo tempo, sem precisar mover seus olhos. Essa forma de atenção rude de homens em relação a mulheres não se trata apenas de reivindicação do espaço público, mas também de reivindicação dos corpos das mulheres como parte do espaço público a ocupar livremente. Questionar o olhar fixo não ajuda a re- verter a situação. Como em um incidente recente, sentada com uma amiga na calçada do bairro de Galata em Istambul, percebi que minha amiga estava sendo objeto dessa atenção. Eu imediatamente perguntei ao homem se algo estava errado. Ele se aproximou, direcionando sua atenção para mim e disse que não olharia se fosse ilegal, alegando assim sua ação como um direito legal. Quais são os limites de uma atenção tão rude? Até que ponto pode ser considerado "apenas olhando" e não "agindo"? Ou será outra forma de silenciar o outro ameaçando-o por meio de uma atenção não-civilizada?

Estudiosas feministas como Margaret Crouch afirmam que tais interações são formas de assédio (CROUCH, 2009, p. 137). Eu concordo que atenção grosseira não é apenas silenciamento, mas também ameaça aos direitos de alguém de agir livre e confortavelmente no espaço público. Crouch também acrescenta que não se trata apenas o assédio quanto ao uso do espaço público, mas também o assédio de rua ou no transporte coletivo, que são grandes problemas para as mulheres em muitos países, e isso significa controlar o comportamento das mulheres nesses espaços (CROUCH, 2009, p. 137).

$\mathrm{Na}$ Turquia, o assédio nas ruas e nos transportes também é um problema importante para as mulheres e o debate foi alimentado no ano passado pelo assassinato de uma jovem de 20 anos, estudante universitária, por um motorista de micro-ônibus, após resistir a um estupro em fevereiro de 2015. Milhares de mulheres contaram seus casos de assédio online em uma campanha que começou após o caso com a hashtag \#sendeanlat (\#tellyourstory ${ }^{7}$ ) (DAVIDSON, 2015). Em um curto período de tempo, mulheres compartilharam milhares de incidentes que enfrentam diariamente em escolas, ônibus, locais de trabalho e ruas.

Em outro incidente recente, um assistente de ônibus supostamente atacou sexualmente uma passageira enquanto ela dormia durante o tempo de duração da viagem. De acordo com relatos da mídia,

7 Tradução livre: Conte sua história, N.T 
o incidente gerou a hashtag \#SapıkMetroKapatılsın, que significa shutdownpervertMetro ${ }^{8}$, que gerou uma tendência nas redes sociais turcas, algumas descrevendo o incidente e como foi tratado como uma desgraça horrível, embaraçosa e desprezível. Neste artigo, o contexto do espaço público é principalmente o da rua e suas extensões, como o transporte público nesses exemplos, além de milhares de histórias de outras mulheres. Essas histórias demonstram que as mulheres são silenciadas em espaços públicos nos termos de Ardener e também difamadas, violadas, mortas e invisibilizadas pelos homens. No entanto, também tenho interesse na forma com que devemos categorizar as mulheres como vítimas. Ao falar sobre esses casos de violações dos direitos corporais, quero salientar que talvez tal atenção não-civilizada também ocorra dentro dos escritos acadêmicos, bem como nas formas de categorizar as mulheres em certos estereótipos, e até mesmo de mulheres para mulheres, incluindo eu. Chandra Talpade Mohanty aborda esta questão em seu ensaio Under Western Eyes: Revisited, afirmando que embora ela não venha do mundo ocidental, como uma acadêmica, é onde ela está localizada:

Sou claramente uma parte da minoria social agora, com todos os seus privilégios; entretanto, minhas escolhas políticas, minhas lutas e visão de mudança me situam ao lado do mundo dos dois terços. Portanto, sou a favor do mundo dos dois terços, mas com os privilégios do mundo do um terço. Falo como uma pessoa situada no mundo do um terço, mas a partir do espaço e da visão - e em solidariedade com comunidades em luta - do mundo dos dois terços. (MOHANTY, 2003, p. 5079).

$\mathrm{Na}$ verdade, ao falar sobre repressão e violação dos direitos humanos das mulheres, como podemos nos abster de categorias? Como podemos evitar ver o feminismo como um en-

8 Tradução livre: Deter o pervertido da condução, N.T.

9 No texto traduzido para o português MOHANTY, 2020, p. 78. Ver nota 5. sinamento do ocidente para o oriente? Para Mohanty, a posição é de criar uma prática transnacional e anticapitalista (MOHANTY, 2003, p. 50910).

\section{- Intervenções artísticas e possibilidades}

Como uma artista com formação jornalística e também acadêmica, eu estou investindo em como a arte pode comunicar, oferecendo soluções alternativas para problemas sócio-políticos existentes. Tendo estudado cânones da arte feminista, como Suzanne Lacy, Valie Export e Guerilla Girls, valorizei cada vez mais as formas com que criaram diferentes métodos para estabelecer conexões entre sua arte, seu corpo e seu papel na sociedade, o que, a longo prazo, contribuiu imensamente para a igualdade de gênero. No ano de 2016 e em outra geografia, a Turquia, eu busco outras possibilidades para criar tais espaços para as mulheres. Uma dessas artistas, Suzanne Lacy (nascida em 1945), é uma figura extremamente significativa no tratamento de questões como estupro, pobreza, racismo e políticas de gênero, assuntos extremamente críticos em relação ao espaço público nos EUA na década de 1970. Em 1977, Lacy realizou seu renomado trabalho, Three Weeks in May, focado na temática do estupro em Los Angeles. Em colaboração com muitas outras artistas, o trabalho incorporou discursos políticos, entrevistas de rádio, comunicados de imprensa, performance art e demonstrações de autodefesa, a fim de aumentar a conscientização sobre esse assunto. Lacy rastreou a ocorrência de estupro durante aqueles 21 dias em um grande mapa exibido no L.A. City Mall. Ao vincular a performance à grupos comunitários, mídia e governo, o trabalho Three Weeks in May tornou-se um exemplo pioneiro de como a arte pode ser feita com referência a questões e problemas sociais (ver Figura 1). Por meio de Lacy, a mídia também se interessou pelo problema e, devido ao diálogo organizado entre artistas, organizações e grupos comunitários, as ações coletivas tornaram-se mais visíveis no espaço público.

10 No texto traduzido para o português MOHANTY, 2020, p. 82. Ver nota 5. 
Figura 1 - Performance Still from Mourning and in Rage Media. (Performance em que os participantes ficam imóveis) Evento Memorial em homenagem às vítimas do assassino em série conhecido como o Estrangulador de Hillside, Los Angeles, CA, 1977.

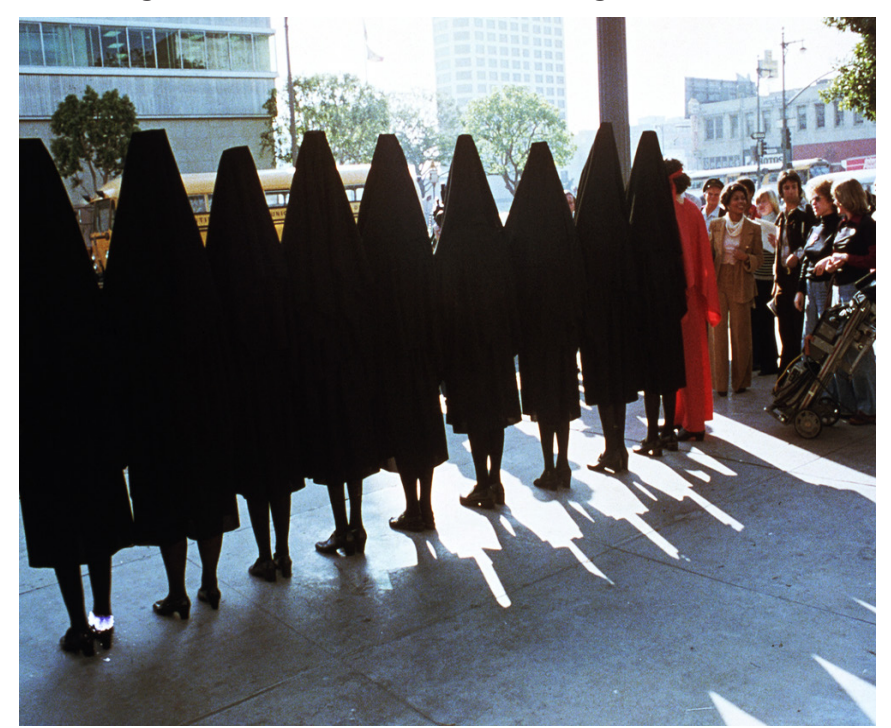

Fonte:Disponível em: https://www.againstviolence.art/ in-mourning-and-in-rage Acesso em: 11 jan. 2021.

Outra artista influente, a austríaca Valie Export (nascida em 1940) desafia as representações de feminilidade no espaço público. O seu aclamado trabalho ActionPants: Genital Panic in Public Space (1969) aconteceu em Munique em um cinema de arte onde cineastas experimentais foram mostrando seu trabalho (ver Figura 2). Export usava calças com um triângulo recortado na altura de sua genitália e caminhava entre as filas de espectadores, expondo-a ao nível do rosto do público sentado. Essa confrontação desafiou o clichê da história da representação das mulheres, tanto no cinema quanto na pintura a óleo, que as retratava como objetos passivos a quem os agenciamentos eram negados.
Figura 2 -Valie Export: Action Pants: Genital Panic in Public Space, 1969.

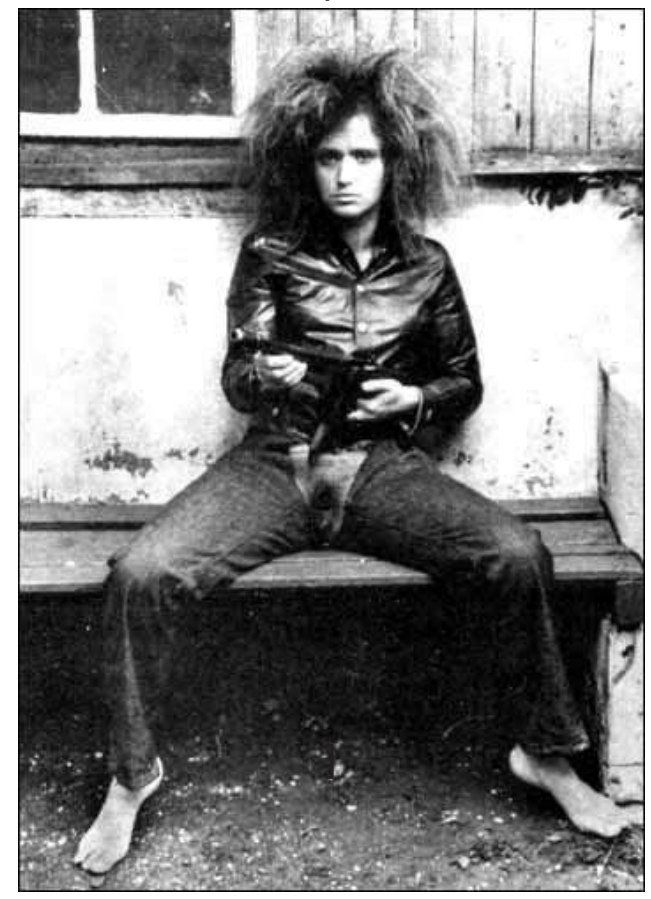

Fonte: Disponível em https://hybridutterance.wordpress. com/2009/10/01/action-pants-1969-valie-export/. Acesso em 11 jan. 2021.

Observando pelo ponto de vista de Ardener, é bastante óbvio ver como as mulheres foram visualmente silenciadas na história da arte como uma subcategoria da teoria dos grupos silenciados. A representação da imagem de uma mulher nua, passiva e convidativa é extremamente questionável e difícil de generalizar. O trabalho das Guerrilla Girls, que visa expor a discriminação sexual e racial no mundo da arte, também aponta para o silenciamento de mulheres ao reproduzir obras de arte conhecidas com seu próprio ponto de vista. O poster abaixo (Figura 3) Do women have to be naked to get into the Met. Museum? mostra uma mulher nua que usa uma máscara de gorila. O pôster abaixo é baseado na famosa pintura de Jean Auguste Dominique Ingres (Figura 4) e enumera alguns fatos: menos de $5 \%$ dos artistas nas Seções de Arte Moderna são mulheres, mas $85 \%$ dos nus são femininos. 
Figure 3 - Guerilla Girls: Do Women Have To Be

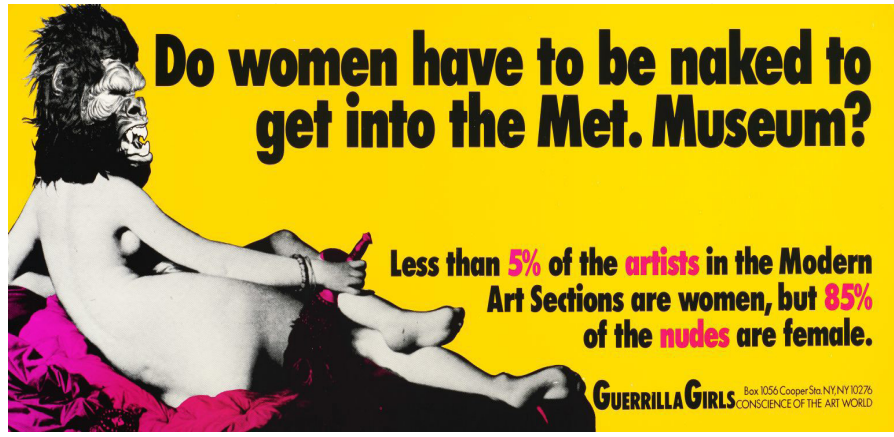

Fonte: Disponível em https://www.artgallery.nsw.gov.au/ collection/works/150.2014.24/. Acesso em 11 jan. 2021.

Figura 4 -Jean Auguste Dominique Ingres, La Grande Odalisque, 1814.

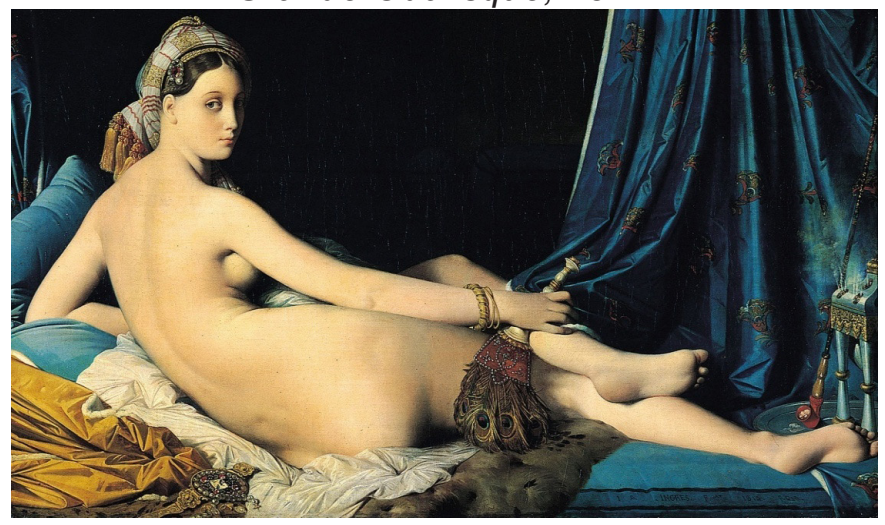

Fonte: Disponível em https://commons.wikimedia.org/ wiki/File:Jean_Auguste_Dominique_Ingres,_La_Grande_Odalisque,_1814.jpg. Acesso em 11 jan. 2021.

O pôster foi originalmente projetado para ser um painel encomendado pelo PublicArtFund de Nova York, mas foi rejeitado por não ser claro o suficiente. As Guerrilla Girls então relataram: "nós então alugamos espaço publicitário nos ônibus de Nova York e divulgamos nós mesmas, até que a empresa de ônibus cancelou nosso aluguel, dizendo que a imagem ... era muito sugestiva e que a figura parecia ter mais do que um leque na mão."

Levando a questão para a Turquia, eu também gostaria de trazer como exemplo o anúncio da artista turca Canan (nascida em 1970, e que se recusa a usar o sobrenome), Nihayetiçimdesin (Finalmente você está em mim) (Figura 5). O trabalho de Canan, exibido em um painel acima da entrada de um cyber café que ela e seu marido possuíam em Istambul na- quela época, foi removido pelo município de Kadıköy no ano de 2000, sob reclamações acerca do trabalho. A artista, que estava grávida no momento, usou a frase Finalmente Você Está em Mim como uma celebração ao seu tão desejado bebê, mas suas palavras foram interpretadas como um ato sexual, como uma mulher que anseia por uma penetração masculina. 0 significado dúbio do trabalho é evidentemente subjetivo e questiona intencionalmente a ambiguidade e a elasticidade da linguagem. No entanto, a remoção do trabalho mostra claramente como a língua é estruturada à luz de uma fantasia masculina unilateral, quando a partir do testemunho da mulher. Quando ela mostra claramente seu entusiasmo por algo dentro dela, será que poderia ser outra coisa que não um órgão sexual masculino? A intervenção no trabalho mostra claramente uma fantasia masculina, uma vez que essa frase é um clichê usado em filmes eróticos, mas também mostra como se torna assustadora para os homens, quando é ouvida no espaço público.

Fantasia e medo ao mesmo tempo, a frase não demonstra nada além do medo de dominação da linguagem pelas mulheres. Ainda assim, o trabalho é bem-sucedido em, pelo menos, levar o público a fazer essas perguntas.

Figura 5 -Canan, Finalmente você está em mim, Painel, 2000.

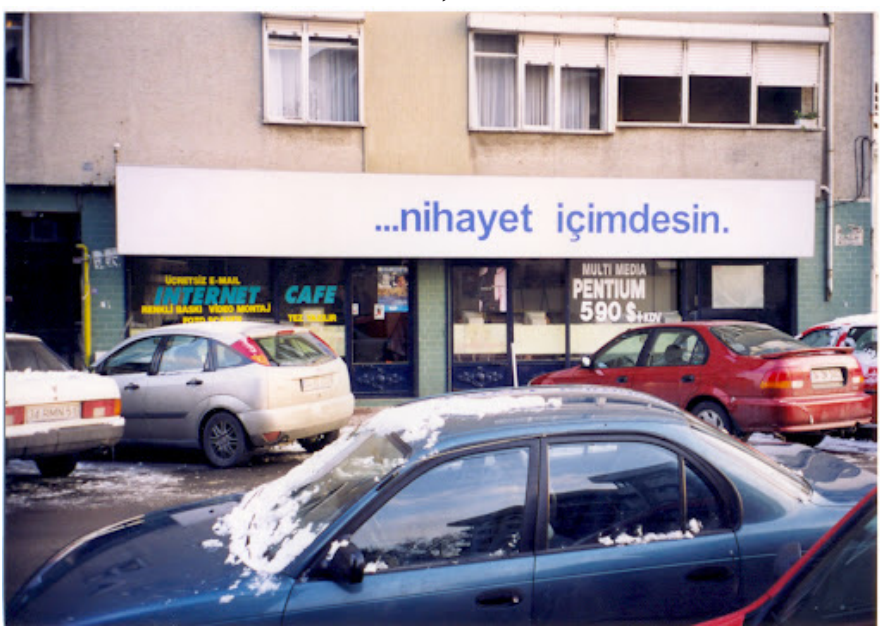

Fonte: Canan, Finally You Are in Me. Disponível em http://www.siyahbant.org/bu-sanat-yapiti-cevreye-zararli. Acesso em 11 jan. 2021. 
Por fim, darei um exemplo do meu próprio trabalho, uma instalação de vídeo que foi desativada pelo município de Istambul apenas três dias após sua inauguração. Localizada no topo do Marmara Pera Hotel, o vídeo era uma animação de 30 segundos, que dizia Eve Finish Your Apple e terminava com uma maçã transformando-se lentamente no rosto de uma mulher (Figura 6). Como resposta às religiões monoteístas, em que a figura Eva é retratada como uma mulher ardilosa que seduz Adão a comer a maçã, queria dar toda a responsabilidade a Eva, pedindo-Ihe para terminar a maçã e reescrever a narrativa. Eu queria re-descrever outra possibilidade de definir Eva.

Meu trabalho foi exibido em um espaço público, em uma tela de 6x9 metros no Marmara Pera hotel e deveria ficar lá por um período de três meses. No entanto, a exibição foi interrompida três dias após a abertura pela polícia municipal, dizendo que causava "poluição visual" e nunca mais foi restabelecida. Nunca recebi uma explicação oficial sobre a definição de poluição visual em uma cidade em que até as pontes são decoradas com luzes de néon à noite.

\section{Figura 6 - Işıl Eğrikavuk, Time To Sing a New} Song, Instalação de Vídeo, 2016.

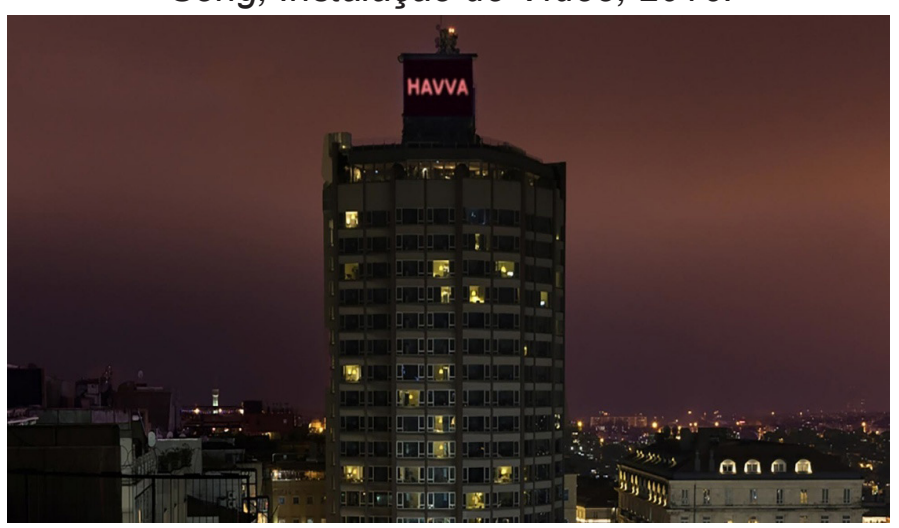

Fonte: Havva. (Time To Sing a New Song).

Cortesia da autora.

À luz desses exemplos, gostaria de sublinhar a capacidade e o poder da arte, que é uma área em grande parte considerada irrelevante para os problemas sociológicos, e oferecer o pensamento artístico como potencial para desafiar normas existentes. Estou investindo em encontrar estratégias artísticas que podem não necessariamente trazer uma solução para o problema existente, mas que possam temporariamente reverter esses modos de controle. No contexto atual de Istambul, quero questionar se uma estratégia artística que envolve dança, corpo e, especificamente o corpo feminino, pode conectar mulheres de diferentes classes e idades para seu empoderamento e desafiar esses mecanismos de controle em espaços públicos, criados por homens. Como ponto de partida, gostaria de estudar a dança do ventre como método artístico de empoderamento.

\section{Dança do Ventre, Opressão ou Empoderamento?}

Qual é a identidade de um(a) Belly Dancer ${ }^{11}$ ? Em primeiro lugar, quando dizemos dançarina(o) do ventre, pensamos nessa pessoa como um homem ou mulher? Na verdade, todos os sexos têm ventre e todos os sexos, mulheres, homens e pessoas trans, bem como pessoas intersexuais também podem dançar. Então, por que associamos imediatamente a palavra a uma mulher seminua, que sacode o corpo e dança, não para entreter a si mesma ou expressar-se, mas apenas para agradar aos outros? Por que a dança do ventre não é considerada auto expressão, e sim um serviço de entretenimento principalmente para o olhar masculino? Por que associamos a dança do ventre, uma prática feita principalmente por mulheres, a uma forma inferior de entretenimento ou mesmo a uma indústria de serviços, em que o corpo nu se torna receptor não apenas do olhar, mas também do dinheiro?

A dança do ventre, dança do Oriente Médio ou dança oriental, como quisermos denominar, há muito tempo é vista como uma forma de dança exótica, sexual e suscetível ao olhar masculino. Multiplicada nas pinturas europeias, escritos de viagens, nos filmes antigos de Hollywood, bem como por ícones pop de hoje, a literatura existente sobre a dança do ventre há muito define-a de forma estereotipada. A

11 Em inglês, a expressão Belly Dancer poderia ser traduzida como dançarina(o) do ventre, pois os vocábulos não indicam gênero. N.T. 
imagem corporal voluptuosa e sensual da dançarina do ventre atraindo o olhar é semelhante à forma com que Said descreveu a imagem construída do Oriente Médio em seu livro Orientalism como "um lugar de romance, seres exóticos, memórias e paisagens assustadoras, experiências marcantes" (SAID, 1979, p. 1).

Figura 7 - Tara Lee, Dançarina do Ventre: imagem representativa.

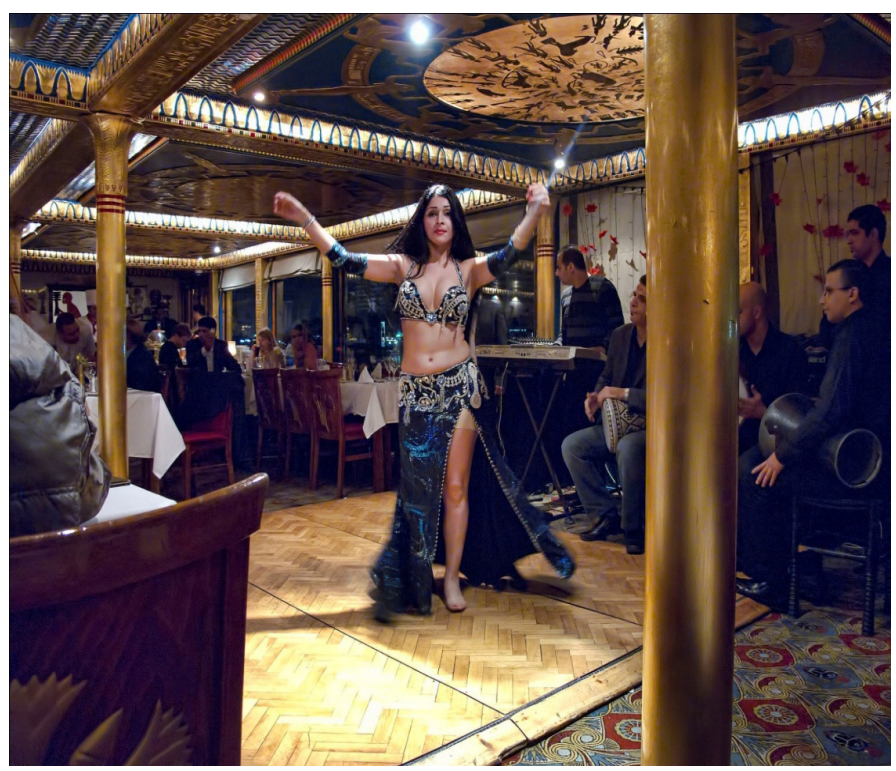

Fonte: Disponível em https://en.wikipedia.org/wiki/Belly_ dance\#/media/File:20111110_Egypt_0421_Cairo_dinner_cruise.jpg. Acesso em 11 jan. 2021.

Embora existam muitos mitos sobre as origens da dança, alguns estudiosos sugerem que tradicionalmente era executada na frente de outras mulheres como parte de celebrações familiares (NIEUWKERK, 1995 , p. 12). Outras fontes descrevem a dança como uma antiga cerimônia de adoração, alegando que a dança feminina estava, na verdade, relacionada à celebração da sexualidade e da fertilidade (BUONAVENTURA, 1998, p. 34-35). Tal abordagem foi apropriada por algumas dançarinas feministas nos Estados Unidos, especialmente na década de 1970, que tentaram recuperar essa forma de dança como estratégia para reconectar seu corpo com a feminilidade. Apoiadas pelo surgimento do "sagrado feminino" nos Estados Unidos na década de 1970, alguns também criaram conexões entre a dança do ventre, a deusa ancestral e as culturas da fertilidade. Essas defensoras feministas da dança do ventre trabalharam para redefinir os estereótipos sexualizados, anteriormente associados à dança e, em vez disso, promoveram a dança do ventre como uma celebração e um despertar das forças criativas femininas (KEFT-KENNEDY, 2005 , p. 50). Apoiada por uma versão popularizada na indústria fitness, até 1979, a American Broadcast Company informou que mais de um milhão mulheres, apenas nos Estados Unidos, estavam tendo aulas de dança do ventre (SELLERS-YOUNG, 1992, p.143).

Apesar de originária da Índia, do Norte da África e do Oriente Médio, tal tentativa de redefinição da dança não é ausente nessas geografias também. Porém, ainda hoje é vista sob a moldura de suas definições orientalistas, onde uma mulher seminua dança para agradar ao olhar do público. Além disso, há um número limitado de trabalhos acadêmicos sobre a dança. De acordo com Keft-Kennedy, embora o interesse acadêmico pela dança do ventre tenha emergido lentamente desde o final dos anos de 1970, as pesquisas tendem a considerar excessivamente a historicização da dança ou são focadas em questões de autenticidade e classificação (KEFT-KENNEDY, 2005 , p. 24). Eu acrescentaria que esse interesse acadêmico, seja qual for o seu o foco, é também, principalmente originário do Ocidente. A literatura acadêmica existente sobre a dança do ventre na Turquia é escassa. Portanto, uma investigação crítica sobre as formas de categorização dança irá destacar uma área que há muito tem sido subvalorizada.

A desvalorização da dança do ventre no Oriente Médio, a meu ver, parece um grande exemplo de repressão da expressão feminina de sexualidade, energia e fertilidade. Nesse caso, o silenciamento não ocorre no nível da linguagem, mas no corpo. Aqui, o processo de emudecimento funciona por meio da descontextualização do propósito da dança. A expressão da feminilidade através da dança do ventre não é censurada nem banida, mas perde seu significado original e é feita de forma a ser categorizada como algo de baixa cultura, sem virtude e banal. Isso não serve mais para as próprias dançarinas, mas privada 
de seu significado, a dança se torna um prazer sexual para o olhar dos homens. Assim como a Odalisca de Ingres (Figura 4), a dançarina do ventre representa não uma mulher real, mas um ser sexualizado.

Para mim, essa recontextualização da dança não é tão diferente da recontextualização do espaço público. O contexto vigente não é democrático e desvaloriza a presença de mulheres. Nesse aspecto, o que será necessário para reverter esses falsos contextos e colocá-los de volta em seus lugares?

\section{Teoria do Grupo Silenciado Hoje e Possibilidades de Coletividade}

Em um artigo recente intitulado Muted Group Theory and Communication: Asking Dangerous Questions, o acadêmico Cheris Kramarae leva a teoria ainda mais adiante e fornece uma resposta de como a teoria pode ser aplicada a condições de hoje. De acordo com Kramarae:

Nos últimos anos, tem havido muita te-
orização que trata explicitamente de es-
forços para incluir o conhecimento e a
criatividade de muitas mulheres, bem
como de homens; essas teorias são ge-
ralmente rotuladas de teorias feministas e
são frequentemente marginalizadas; seu
potencial explicativo ainda é frequente-
mente limitado a discussões e estudos
sobre gênero. (KRAMARAE, 1999, p. 55).

As palavras de Kramarae mostram que embora o movimento feminista tenha ganhado um importante impulso nos anos 1970 e 1980 nos EUA, ainda há um longo caminho a percorrer. Questões relacionadas à raça, gênero e identidade ainda são grandes plataformas de debate fora das salas de aula na vida cotidiana. Para transportar as palavras de Kramarae para a Istambul de hoje, e dado o clima sócio-político corrente, estou reivindicando que esse silenciamento das mulheres ainda é um grande problema em todos os segmentos da sociedade, incluindo questões críticas como desigualdade de direitos, inequidade de cidadania, violência de rua e agressão sexual, opressão, assédio e silenciamento.
Minha única crítica à Teoria do Grupo Silenciado se aplica aqui, onde afirmo que a ela apresenta as desigualdades em relação às mulheres, porém não oferece alternativa em como corrigi-las ou recuperá-las. Acredito que isso a localiza em terreno instável. A teoria ajuda a identificar muitas das formas assimétricas de relacionamento criadas por meio do silenciamento das mulheres, as coloca em destaque e nos deixa em uma situação de vitimização em termos de posicionamento, normas e estudos. A respeito disso, considero que a arte pode intervir e agir como um catalisador na correção de clichês, a fim de recolocá-los para atuar de forma diferente no espaço público. Somente pela arte é possível imaginar um espaço se abrindo para a mudança.

Dado esse contexto, eu gostaria de perguntar: poderia uma forma de dança ancestral criar o espaço para o empoderamento das mulheres e se tornar uma estratégia exemplar para lidar com olhar opressor? Ou a dança em si cai em uma categoria de opressão? Em um contexto onde os papéis de gênero são definidos por hierarquias, que tipo de possibilidades a dança do ventre abre para as mulheres alcançarem poder?

Na forma de intervenção artística, estou procurando maneiras de conectar a dança do ventre ao empoderamento feminino e ver como essa conexão pode abrir um espaço para mulheres reivindicarem sua posição contra a discriminação. Pergunto ainda, que tipo de abordagem artística pode levar a dança à esfera do espaço público e subverter os papéis entre homens e mulheres, entre quem contempla e quem dança, e entre o opressor e o oprimido.

Eu gostaria de imaginar, ao invés de perguntar, como seriam sessões de dança coletivas em espaços públicos de Istambul, em ônibus, metrôs e parques, onde mulheres em roupas do dia-a-dia usam movimentos de coreografias de dança do ventre em uma forma de protesto contra as maneiras pelas quais as mulheres têm sido representadas no espaço público e na cultura. Eu também gostaria de imaginar que esta forma de dança coletiva poderia dar voz a nossos corpos e nossas identidades na forma como já foi um dia, e iniciar uma nova forma 
de comunicação e de existência no espaço público. Se nossa voz está silenciada, talvez sejam nossos corpos que possam ter essa voz novamente. Questões relacionadas ao corpo das mulheres, especialmente relacionadas a controle e assédio dos corpos femininos são tão oportunas e acredito que tal investigação é relevante não apenas às comunidades artísticas, mas também em esferas mais amplas.

\section{Conclusão}

Ao longo da trajetória desse artigo, baseei meus argumentos na Teoria do Grupo Silenciado de Shirley Ardener, aplicando a teoria à Istambul de 2016. Essa teoria mostra as relações assimétricas em uma sociedade, em que alguns grupos têm menos voz do que outros ou são completamente excluídos. Tentei identificar como isso se aplica à sociedade de hoje em Istambul, não apenas através do silenciamento da linguagem de e para as mulheres, mas também através do silenciamento dos corpos femininos.

A Teoria do Grupo Silenciado tem origem na antropologia. No entanto, ao conectar a disciplina de comunicação à disciplina de artes visuais, estou argumentando que as duas não estão diretamente relacionadas, mas têm um imenso potencial de aprendizagem e crescimento uma com a outra. A luta pelo feminismo está além das disciplinas de estudo acadêmico. No entanto, cada uma tem seus próprios métodos e trajetórias na luta contra o patriarcado, tanto na vida cotidiana quanto no nível teórico. Ao reunir esses campos com a arte e a dança, gostaria de abrir outra porta, em que a luta se torna mais forte na teoria e mais criativa na prática.

As mulheres têm muitas práticas abandonadas, muitas palavras abandonadas e muitas ações abandonadas ao longo da história porque essas categorias foram banidas, consideradas imorais ou inferiores pelo patriarcado e suas instituições. Ao identificar essas categorias e recuperá-las instaura-se um chamado ao empoderamento. Somente através da reivindicação da propriedade da linguagem, do corpo, do pensamento e da ação e aplicando-as coletivamente no dia-a-dia, essas práticas abandonadas podem ser reivindicadas de volta. A dança do ventre é apenas uma das muitas práticas abandonadas ou descontextualizadas, mas demonstra o quanto os corpos das mulheres têm sido controlados, dirigidos e penetrados ilegalmente.

Ao longo desse artigo, transitei da Teoria do Grupo Silenciado para o espaço público, para as práticas e intervenções artísticas e as ações de guerrilha feminista. Conectando as disciplinas, vejo que há e haverá novas possibilidades que se abrem para a mudança. Para concluir com uma citação da própria Ardener:

Frequentemente somos como o cachorro girando em círculos perseguindo o próprio rabo. Se o cachorro o agarra com os dentes, descobrirá não o "outro", mas ele mesmo! Da mesma forma, ao enfrentar as apresentações supostamente objetivas de novos fatos, é provável que encontremos nossas próprias imagens folclóricas olhando de volta para nós. (ARDENER, 2005, p. 54).

\section{Referências}

ARDENER, Shirley. Muted group theory excerpts. Women and Language, v. 28, n. 2, p. 50-72, 2005.

BUONAVENTURA, Wendy. Serpent of the Nile: Women and Dance in the Arab World.New York: Interlink, 1998.

CROUCH, Margaret. Sexual harassment in public places. Social Philosophy Today, v. 25, p. 137-148, 2009.

DAVIDSON, $\mathrm{H}$. Rape and murder of young woman sparks mass Twitter protest in Turkey. The Guardian. TheGuardian. com, v. 17, 2015. Disponível em: http://www.theguardian.com/world/2015/feb/17/ turkish-woman-ozgecan-aslans-sparks-anti-violence-campaign-sendeanlat Acesso em: 06 Abril 2021.

GARDNER, Carol Brooks. Passing by: Gender and public harassment. Univ. of California Press, 1995. 
GOFFMAN, Erving. Behavior in public places. New York: Simon and Schuster, 1963.

KEFT-KENNEDY, Virginia. Representing the belly-dancing body: feminism, orientalism, and the grotesque.Wollongong: University of Wollongong, 2005.

KRAMARAE, Cheris . A. Revolutionary View of Communication; CherisKramarae's Theory of Muted Groups. Women and Language, n. 22, 1999.

LOFLAND, Lyn H. A World of Strangers; Order and Action in Urban Public Space. New York: Basic, 1973.

MOHANTY, Chandra Talpade. "Under western eyes" revisited: Feminist solidarity through anticapitalist struggles. Signs: Journal of Women in culture and Society, v. 28, n. 2, p. 499-535, 2003.

NIEUWKERK, Karin V. A trade like any other: Female singers and dancers in Egypt. University of Texas Press, 2010.

SAID, Edward W. Orientalism. New York: Vintage, 1979.

SELLERS-YOUNG, Barbara. Raks El Sharki: Transculturation of a Folk Form. The Journal of Popular Culture, n.26 v.2 , p. 141-52, 1992.

\section{Agradecimentos}

Agradecemos imensamente à autora e à revista Kadin/Woman 2000 que nos autorizaram a traduzir e a publicar esse artigo na Revista Cena. O original foi publicado em 2017 no volume 18, número 2 da revista na Kadın/Woman 2000 - Journal for Women'sStudies. A presente tradução para o português foi feita pela Dra. Márcia Donadel com colaboração da Dra. Andréa Moraes.
Recebido: 14/01/2021

Aceito: $28 / 01 / 2021$

Aprovado para publicação: 19/04/2021

Este é um artigo de acesso aberto distribuído sob os termos de uma Licença Crea- tive Commons Atribuição 4.0 Internacional. Disponível em: $<$ http://creativecommons.org/licenses/by/4.0>.

This is an open-access article distributed under the terms of the Creative Commons Attribution License 4.0 International. Available at: <http://creativecommons.org/licenses/by/4.0>.

Ce texte en libre accès est placé sous licence Creative Commons Attribution 4.0 International. Disponible sur: <http://creativecommons.org/licenses/by/4.0>. 